\title{
ARABIDOPSIS POLLEN ABORTION MUTANT 2, Encoding an Unknown Protein with Three WD40- Repeats, Is Essential for Late Pollen Mature in Arabidopsis thaliana
}

\section{Zhaoxia Ma}

Kunming University

\section{Xueqin Zhang}

China Agricultural University

\section{Liqun Chen}

China Agricultural University

\section{Guobin Zhang}

Kunming University

Yue Liu

China Agricultural University

De Ye

China Agricultural University

Hongyu Yang ( $\square$ yanghongyukm@126.com )

Kunming University https://orcid.org/0000-0001-5778-5396

Research article

Keywords: Arabidopsis thaliana, AtAPAM2, late pollen mature, WD40 protein

Posted Date: July 23rd, 2019

DOl: https://doi.org/10.21203/rs.2.11828/v1

License: (c) (i) This work is licensed under a Creative Commons Attribution 4.0 International License. Read Full License 


\section{Abstract}

Background In flowering plants, pollen formation is a very complex process. It is strictly regulated by various genetic factors. Some of these factors have been identified, but the regulatory mechanism concerning the process of late pollen maturing remains unknown. Results Previously we identified and reported an ARABIDOPSIS POLLEN ABORTION MUTANT 2 (APAM2) gene which was required for pollen formation in Arabidopsis thaliana. In this study, we further analysed the phenotype of atapam 2 and the subcellular localisation of AtAPAM2. Mutation in AtAPAM2 drastically affected male gametophytic function, impacted the late pollen mature process, and resulted in mature pollen grains from atapam2/+ plants being shrivelled and dead. It was expressed among seedlings, roots, stems, leaves, siliques, flowers, and pollen grains. However, its expression levels in flowers and pollen grains were much higher than in other tissues. Gene AtAPAM2 encodes an unknown protein with three WD40-repeats with localisation in plasma membrane and nucleus, and homologous proteins exist in many species. Conclusions We determined that AtAPAM2 may play a role in pollen formation and other development processes by interacting with other proteins, but we did not identify the protein that interacts with it.

\section{Background}

The WD40 domain is one of the most abundant domains in eukaryotic genomes, and consists of 44-60 amino acid (aa) residues with a glycine-histidine di-peptide close to the N-terminal and a tryptophanaspartic acid (WD) di-peptide at the C-terminal end [1]. When present in a protein, the WD40 motif is typically found as several (usually 4-10) tandem repeat units and they usually function as a proteinprotein or protein-DNA/RNA interaction platform $[2,3,4]$. The first identified WD40 domain was the $\beta$ subunit of heterotrimeric $G$ protein. The WD40 repeats form four-antiparallel $\beta$-sheets which in turn fold into a higher-level structure denoted the $\beta$-propeller. At least four repeats are believed to be required to form a $\beta$-propeller. In G $\beta$, which contains seven WD40-repeats, the first and last repeats participate in the same propeller blade, potentially reinforcing the structure $[5,6]$.

In the Arabidopsis thaliana genome, 269 proteins containing at least one copy of the WD40 motif were identified, and of these 237 contain four or more recognisable copies. These 237 proteins can be classified into 143 distinct families, and are components of basic cellular mechanisms [2].

The WD40 proteins are involved in a variety of cellular functions; for example, AtNEDD1, a WD40 repeat protein is associated with animal NEDD1/GCP-WD protein, which interacts with the $\mathrm{y}$-tubulin complex and participates in microtubule organisation during cell division [7]. The WD40 protein TRANSPARENT TESTA GLABRA1 (TTG1) regulates several developmental and biochemical pathways in Arabidopsis, including formation of hairs on leaves, stems, and roots, and production of seed mucilage and anthocyanin pigments [8]. The WD40 proteins also participate in the progress of gametophytic development, and several have been identified. Gene SLOW WALKER1 (SWA1) encodes a protein with six WD40 repeats that localises in the nucleolus in interphase cells, which are involved in 18S ribosomal RNA biogenesis, and is essential for gametogenesis in Arabidopsis [9]. The Arabidopsis Yaozhe (YAO) is a nucleolar WD40 
protein involved in embryogenesis and gametogenesis [10].Rice Immature Pollen1RIP1),containing five WD40 repeats, regulates late pollen development in rice [11]. The OsLIS-L 1 gene encoding the lissencephaly type-1-like protein with WD40 repeats is involved in plant height and male gametophyte formation in rice [12]. The LuWD40-1 gene encoding a WD40 repeat protein regulates growth and pollen viability in flax (Linum usitatissimum L.) [13]. The JINGUBANG gene encodes a putative hydrophilic protein containing seven WD40 repeats, which is a negative regulator of pollen germination and prevents pollination in moist environments [14].

In recent years, although a number of WD40 proteins have been identified, their functions are little known. Yang et al. isolated four gametophytic male-sterile mutantsapam1-apam4)in Arabidopsis [15]. Mutation of ATAPAM2 (ARABIDOPSIS POLLEN ABORTION MUTANT 2) drastically affected male gametophytic function and the Ds element was inserted in the $18^{\text {th }}$ intron of $A t 3 g 50590$ [15]. In this study, we report the characterisation of atapam2. Gene AtAPAM2 is constitutively expressed including in seedlings, roots, stems, leaves, siliques, flowers, and pollen grains. It encodes an unknown protein with three WD40repeats that localises in plasma membrane and the nucleus. Homologous proteins of AtAPAM2 exist in many species, and we speculate that this protein may play a role in pollen formation and other development processes by interacting with other proteins.

\section{Results}

\section{The atapam2/+ Mutant is Defective in Mature Pollen Grains}

We crossed the atapam2/+ plant with the quartet1 (qrt1) mutant to obtain the atapam2/+; qrt1/qrt1 plants for tetrad analysis. The qrt1 mutant caused the pollen grains not to separate from the tetrad, but had little effect on growth of the pollen tube [16]. Therefore, the atapam2/+; qrt1/qrt1 plants produced a tetrad consisting of two qrt (representing wild type) pollen grains and two atapam2 pollen grains. Scanning electron microscopy (SEM) showed that all four pollen grains in the tetrad from qrt1 plants had normal morphology (Fig. 1a), yet the atapam2/+; qrt1/qrt1 plants had only two normal pollen grains (Fig. 1b). Alexander staining (Fig. 1c and 1d) and 4囚,6-diamidino-2-phenylindole (DAPI) staining showed the same results (Fig. 1e-1h). These results showed that the AtAPAM2 mutation affected male gametophytic function.

Because mature pollen grains from atapam2/+ were shrivelled and had no vitality, we were interested in how the mutation influenced development of pollen grains. The DAPI staining was used to investigate at which developmental stage pollen became abnormal (Fig. 2). Before the $12^{\text {th }}$ anther development stage occurred, the developing nuclei of atapam $2 /+$ pollen grains were of normal phenotype, as were wild-type pollen grains (Fig. $2 a-2 c$ and $2 k-2 m$ ). However, when anthers developed to the $12^{\text {th }}$ stage in which pollen grains had developed three nuclei, the pollen grains began to turn abnormal (Fig. $2 \mathrm{~d}$ and $2 n$ ). The mutant grains were smaller than normal pollen grains in bright field image and their nuclei began to 
disappear under UV-light (Fig. $2 d$ and $2 n$ ). By the $13^{\text {th }}$ stage, the nuclei of mutant pollen grains had disappeared completely (Fig. 2e and 2o).

To further determine the results of DAPI staining, the different development stages of buds were embedded in resin. Then we obtained transverse sections of anthers from wild-type and atapam2/+ plants using the semi-thin section method (Fig. 3). The results showed that in the $11^{\text {th }}$ stage of anther development or before, the appearance and size of pollen grains from mutants were the same as for wild type (Fig. 3a-3d). However, in the $12^{\text {th }}$ stage of anther development, anthers were cracking and pollen grains were shed from anthers. Transverse sections of anthers showed that some pollen grains were of irregular appearance and were not as smooth as the wild type (Fig. 3e and 3f). Combining the results of DAPI staining with semi-thin sections, we conclude that pollen grains of atapam2/+ mutant began to turn abnormal at the $12^{\text {th }}$ anther development stage.

Next, we used transmission electron microscopy (TEM) to observe differences in pollen wall structure between wild-type and atapam2 pollen (Fig. 4). Mature atapam2 pollen had characteristic wrinkled intine (Fig. 4c-4e), which was smooth in wild type and closely connected to the inner side of nexine (Fig. 4a and $4 \mathrm{~b}$ ). Mutant pollen also had deformed cytoplasm (Fig. 4c-4e).

At the $11^{\text {th }}$ stage of anther development, pollen grains from atapam2/+ mutants were normal, with two sperm cell nuclei and a vegetative nucleus, suggesting that pollen grains had finished the second mitosis process. But at the $12^{\text {th }}$ stage, pollen grains from atapam $2 /+$ mutant began to turn abnormal. During this stage, the three nuclei pollen grains completed the process of dehydration and the mutation may have affected this process.

\section{The Phenotype of atapam2/+ is Caused by a Ds Insertion in AtAPAM2}

In a previous study, thermal asymmetric interlaced PCR was used to localise the mutation site in atapam2. Sequence analysis indicated that the Ds element was inserted in the $18^{\text {th }}$ intron of At3g50590 [15]. To confirm that the atapam2/+ mutant phenotype was caused by the $D s$ insertion in this gene, we subcloned the full-length genomic DNA fragment of At3g50590, including the promoter and 5区 and 3区 UTRs into the pCAMBIA1300 vector. Then, this construct was introduced into atapam2/+mutant plants. Transgenic lines were screened by MS culture medium containing kanamycin and hygromycin. The selfpollinated $T_{1}$ transgenic seeds were plated on MS culture medium containing kanamycin to determine the segregation ratio of $D s$. The $\mathrm{Kan}^{\mathrm{R}}: \mathrm{Kan}^{\mathrm{S}}$ segregation ratio was approximately 2:1 for most of the transformant lines (19 of 25). The complemented mutant plants produced offspring of atapam2/+ mutation homozygotes in $\mathrm{T}_{2}$ and subsequent generations. When pollen grains from the two independent complemented lines homozygous for the atapam2/+ mutation were observed by SEM, Alexander staining assay, and DAPI staining assay, the configuration of surface, vitality, and nuclei development were 
returned to the level of wild type (Fig. $5 \mathrm{c}, 5 \mathrm{f}, 5 \mathrm{i}$, and $5 \mathrm{I}$ ). At the same time, we calculated the abnormal rate of pollen grains from the two complemented lines, and found about 1.28\% (8/624) and $1.42 \%(10 / 700)$ of pollen grains were abnormal, respectively (Fig. $5 \mathrm{~m}$ ). These results demonstrate that the defect in male gametophytic function in atapam2/+ plants was fully complemented by At3g50590 full-length genomic DNA.

To validate this result, atapam2-2 (SAIL_1288_C09) was obtained from the seed stocks of the Arabidopsis Biological Resource Center (ABRC). The atapam2-2 is a T-DNA insertion mutant of Columbia (Col) background. Using a T-DNA left-border primer Lba1 and a gene-specific primers (atapam2-2-F and atapam2-2-R) (Table 1) for PCR analysis, we confirmed that T-DNA was inserted in the $13^{\text {th }}$ exon (Fig. 8a). The atapam2-2 mutant carried a Basta ${ }^{\mathrm{R}}$-selective marker. The self-pollinated atapam2-2/+ progeny exhibited a Basta ${ }^{\mathrm{R}}$ Basta $^{\mathrm{S}}$ segregation ratio of approximately 1:1 (1590:1500) (Table 2) rather than 3:1. We also used SEM to observe the surface of pollen grains from atapam2-2/t, and found about $50 \%$ $(134 / 271)$ of pollen grains were shrivelled (data not shown). These findings are consistent with previous results concerning atapam2/+ plants [15], and confirm that the defect in the male gametophyte in atapam2/+ was caused by mutation in At3g50590.

\section{AtAPAM2 is Constitutively Expressed and Highly Expressed in Flowers and Pollen Grains}

To understand the function of AtAPAM2, we used RT-PCR to assess its expression pattern. The RNA was isolated from various wild-type plant tissues including seedlings, roots, stems, leaves, inflorescences, and siliques. Then the RNA was reverse-transcribed to cDNA. The RT-PCR analyses showed that AtAPAM2 was ubiquitously expressed in many tissues, was constitutively expressed, and highly expressed in inflorescences (Fig. 6a).

To further study the expression pattern of AtAPAM2, the promoter fragment of AtAPAM2 was incorporated into GUS reporter gene and introduced into wild-type plants. In the $\mathrm{T}_{2}$ transgenic plants harbouring this fusion, GUS staining signals were detected in seedlings, roots, leaves, inflorescences, flowers, siliques, and pollen grains (Fig. 6b-6h). This further demonstrated that AtAPAM2 was expressed constitutively.

\section{Subcellular Localisation of AtAPAM2 Protein}

To further study the function of AtAPAM2 protein, the GFP-AtAPAM2 fusion protein under control of the 35 S promoter (p35S:GFP-AtAPAM2) was constructed. This construct was transformed into leaves of Nicotiana benthamiana for transient expression and Arabidopsis wild-type plants for stable expression. Both in epidermal cells of $N$. benthamiana (Fig. 7a-7c) androots of Arabidopsis (Fig. 7d-7f), the GFP signals indicated AtAPAM2 localisation in plasma membrane and nucleus. 


\section{AtAPAM2 Encodes a Putative WD40-repeat Protein and is Evolutionarily Conserved}

The AtAPAM2 mRNA encodes a putative WD40-repeat protein (Fig. 8b) of 1614 aa and contained three WD40-repeat domains (Fig. 8c). We used the entire aa sequence of AtAPAM2 to carry out a basic local alignment search tool (BLAST) search from NCBI. The results showed several proteins with $>60 \%$ aa sequence similarity to AtAPAM2 in higher plants. Specifically, AtAPAM2 had $98 \%$ identity with EOA23389.1 of Capsella rubella, 96\% with XP_002876038.1 of Arabidopsis lyrata subsp. lyrata, $77 \%$ with XP_002522312.1 of Ricinus communis, 76\% with EOX91354.1 of Theobroma cacao, $76 \%$ with XP_004161728.1 of Cucumis sativus, 75\% with XP_004232045.1 of Solanum lycopersicum, and 68\% with EEC84558.1 of Oryza sativa (Fig. 8d). The above are WD40-repeat proteins, but of unknown function.

The AtAPAM2 has three WD40-repeats and in eukaryotes this domain usually functions as a proteinprotein or protein-DNA/RNA interaction platform $[1,2]$. In order to understand the function of this protein, we made use of the WD40 domain to carry out a yeast two-hybrid assay, with the aim of finding the protein that interacted with it; however, this was not successful.

\section{Discussion}

In flowering plants, the male gametophyte plays a crucial role in plant fertility and crop production by producing and transferring male gametes to embryos for double fertilisation. The male gametophyte is derived from the anther, which is the male sexual organ. Formation of the male gametophyte involves several important steps. First, reproductive cells divide and microspore mother cells form. Then, the microspore mother cells undergo meiosis and produce tetrad microspores surrounded by callose. Later, the callose is degraded by callose enzyme, releasing the haploid microspores. The individual microspores further form three-celled pollen grains, comprising a larger vegetative cell and two smaller sperm cells. The three-celled pollen grain further undergoes dehydration to form a mature pollen grain [17]. The dehydration of pollen grains is very important for maintaining maximum pollen viability so that pollen grains can tolerate various environmental stresses after release from the anther [18]. Defects in any of these steps will affect pollen formation or male gametophytic function $[17,19,20]$. In recent years, many mutants with altered processes of pollen formation have been identified in Arabidopsis, rice, and maize. Because of both male and female gametogenesis defects, loss-of-function of nucleoporin NUP1 in Arabidopsis caused fertility defects. The ovules are arrested during meiosis, and pollen grains are aborted at mitosis I [21]. Loss of $A P 1 G$ function compromised dynamic vacuolar remodelling during pollen development and impaired vacuolar acidification of pollen, which resulted in male gametophytic lethality due to defective pollen development [22]. A conserved glycerol-3-phosphate acyltransferase gene OSGPAT3 plays an important role in regulating anther wall degradation and pollen exocrine formation in rice [23]. Gene OsMS1 regulates tapetal programmed cell death and pollen exine formation in rice; it functions as a transcriptional activator and interacts with known tapetal regulatory factors through its 
plant homeodomain [24]. Loss-of-function of OSTKPR1 delays degeneration of the tapetum, reduces the lipid level of the anther cuticle, disrupts the Ubisch body and pollen exine formation, and results in complete male sterility [25]. Abnormal Pollen Vacuolation1 (APV1),, a tapetum-specific gene, affects anther cuticle and pollen exine formation in maize. The apv1 mutant was completely male sterile [26].

In the present study, we reported the characterisation of atapam2, which affects pollen maturation. It was widely expressed in seedlings, roots, stems, leaves, siliques, flowers, and pollen grains. Gene AtAPAM2encodes an unknown protein with three WD40-repeats that localises in plasma membrane and nucleus. Homologous proteins of AtAPAM2 exist in many species, and we speculate that this protein may interact with other proteins and play a role in pollen formation and other developmental processes.

\section{Conclusions}

We determined that AtAPAM2 protein may play a role in pollen formation and other development processes by interacting with other proteins, but we did not identify the protein that interacts with it.

\section{Methods}

\section{Plant Materials and Mutant Isolation}

The plants used were of Landsberg erecta (Ler) and Colombia (Col) backgrounds. The Ler and Col seeds were propagated and preserved in the laboratory of YeDe (China Agricultural University). The seeds were surface-sterilised and pre-germinated on MS-salt agar plates with or without $50 \mu \mathrm{g} / \mathrm{mL}$ of kanamycin (E004000, Sigma, USA) or $25 \mu \mathrm{g} / \mathrm{mL}$ hygromycin (Roche, Mannheim, Germany) or $10 \mu \mathrm{g} / \mathrm{mL}$ Basta (45520, Sigma, USA) at $22^{\circ} \mathrm{C}$ with a $16 / 8 \mathrm{~h}$ of light/dark cycle. The plants were grown in soil at $22^{\circ} \mathrm{C}$ under the same light cycle as for seed germination. The $D s$ insertion line was generated and mutants selected according to methods described previously [27]. The SALK T-DNA insertion lines were obtained from the ABRC (http://www.arabidopsis.org/).

\section{Phenotypic Characterisation of Mutant}

Morphological observations of pollen grains by SEM were carried out as previously described [28]. The DAPI staining was performed as previously described [29]. Pollen viability was assayed using Alexander's staining [30]. For semi-thin section analysis, developing anthers were fixed overnight in a fixation solution of $5 \%(\mathrm{v} / \mathrm{v})$ glutaraldehyde and $4 \%(\mathrm{v} / \mathrm{v})$ paraformaldehyde $(\mathrm{pH} 7.2)$ and then rinsed three times with 0.1 $\mathrm{M}$ phosphate buffer, post-fixed in $1 \%$ osmium tetroxide for 3-4 $\mathrm{h}$, and rinsed three times with $0.1 \mathrm{M}$ phosphate buffer again. The samples were dehydrated through $30 \mathrm{~min}$ of exposure to a series of ethanol/water mixtures $(30,50,70,80,90$, and $100 \%$ ethanol) and $100 \%$ epoxypropane for two times. Subsequently, samples were transferred to a 1:1 dry epoxypropane:resin mix [31] on a rotator (12 h) and 
infiltrated in a 1:3 dry epoxypropane:resin mix for an additional $12 \mathrm{~h}$ before transferring to freshly mixed resin. Following two fresh resin changes, the materials were polymerised in moulds $\left(70^{\circ} \mathrm{C}\right.$ for $\left.8-10 \mathrm{~h}\right)$ [31]. Semi-thin sections ( $1.0 \mu \mathrm{m}$ thick) were cut using a glass cutter on a Leica RM2265 microtome (Leica, Wetzlar, Germany). The sections were dyed with toluidine blue and viewed under an optical microscope (DM2500, Leica, Wetzlar, Germany). The TEM of pollen grains was performed as described previously [32].

\section{Molecular Cloning of AtAPAM2 and Complementation Experiments}

The full-length AtAPAM2 genomic DNA fragment was amplified by PCR with primers AtAPAM2-C-F and AtAPAM2-C-R (Table 1). For complementation experiments, the full-length AtAPAM2 genomic DNA fragment was subcloned into pCAMBIA1300 vector (CAMBIA, Canberra, Australia) and introduced into atapam2/+ heterozygous plants using the Agrobacterium tumefaciens-mediated infiltration method. The transformant plants were selected in MS medium containing $50 \mathrm{mg} / \mathrm{L}$ of kanamycin and $25 \mathrm{mg} / \mathrm{L}$ of hygromycin. The homozygous transformant plants were selected in $\mathrm{T}_{2}$ generations and used for further analyses.

\section{Analysis of Expression Pattern}

The promoter fragments of AtAPAM2 were amplified using $L A$ Taq and Pfu DNA polymerase (Takara, Dalian, China) with the gene-specific primers AtAPAM2-P-F and AtAPAM2-P-R (Table 1). The resulting fragments were subcloned upstream of the GUS reporter gene in pCAMBIA1300 Ti-derived binary vector and introduced into wild-type plants. Transformation and GUS activity analysis were carried out as described previously $[27,33]$.

For the RT-PCR assay, total RNAs were extracted from roots, stems, leaves, inflorescences, and siliques of 5-week-old wild-type and 10-day-old transformant seedlings, respectively, using an RNAprep Pure Plant Kit (Tiangen, Beijing, China) according to the manufacturer's instructions. First-strand cDNA was synthesised from $1 \mu \mathrm{g}$ of total RNA using the M-MLV reverse transcriptase from Invitrogen (CA, USA) according to the manufacturer's instructions. The gene-specific primers AtAPAM2-RT-F and AtAPAM2-RT-R were used for PCR reactions. TUBULIN8 expression level was applied as the internal control by including the specific primers TUBULIN-F and TUBULIN-R (Table 1).

\section{Subcellular Localisation Assay of the AtAPAM2 Protein}

The AtAPAM2 cDNA fragment was amplified by PCR using the primers AtAPAM2GFP-F and AtAPAM2GFP-R (Table 1) and then cloned into the modified pCAMBIA1300 vector to generate the fusion protein-expressing cassette p35S:GFP-AtAPAM2. The resulting construct was transformed into leaves of 
$N$. benthamiana for transient expression and Arabidopsis wild-type plants for stable expression. The GFP signals were observed under a Leica DM2500 microscope as previously described $[34,35,36]$.

\section{Abbreviations}

DAPI: 4',6-Diamidino-2-Phenylindole; SEM: Scanning Electron Microscope;

TEM: Transmission Electron Microscope; GUS: $\beta$-Glucuronidase;

RT-PCR: Reverse transcription-Polymerase Chain Reaction;

GFP: Green Fluorescent Protein; BLAST: Basic Local Alignment Search Tool.

\section{Declarations}

\section{Ethics approval and consent participate}

Not applicable.

Consent to publish

Not applicable.

\section{Availability of data and materials}

The datasets used and/or analysed during the current study are available from the corresponding author on reasonable request.

\section{Competing interests}

The authors declare that they have no competing interests

\section{Funding}

This work was supported by the National Natural Science Foundation of China (31760078 and 30860121). The funders did not play any roles in the design of the study, collection, analysis, and interpretation of the relevant data, and writing the manuscript.

\section{Author Contributions}

The work presented here was carried out in collaboration among all the authors. $Z M, Y L$, and $G Z$ performed the experiments, analysed data, and contributed to writing the manuscript. HY designed the project, analysed data, wrote the manuscript, and obtained funds to support the project. DY contributed to 
performing the experiment and manuscript writing. XZ and LC helped to perform the experiments. All authors have read and approved the final manuscript.

\section{Acknowledgements}

Not applicable.

\section{Authors' Information}

Zhaoxia Ma, Email: zxma0402@126.com, Address: Yunnan Key Laboratory for Basic Research on Bone and Joint Diseases \&Yunnan Stem Cell Translational Research Center, Kunming University, Kunming, Yunnan 650214, P. R. China.

Xueqin Zhang, Email: zhangxq711-1@163.com; Liqun Chen, Email: chenliqun@cau.edu.cn; De Ye, Email: yede@cau.edu.cn, Address: College of Biological Sciences, China Agricultural University, Beijing 100193, P. R. China.

Guobin Zhang, Email: zgb1982@126.com; Hongyu Yang, Email: yanghongyukm@126.com, Address: College of Agriculture and Life Sciences, Kunming University, Kunming, Yunnan 650214, P. R. China.

YueLiu, Email: liuyue984@126.com;Address: College of Life Sciences, Yunnan Normal University, Kunming, Yunnan 650500, P. R. China.

\section{References}

1. Neer EJ, Schmidt CJ, Nambudripad R, Smith TF. The ancient regulatory-protein family of WD-repeat proteins. Nature. 1994; 371: 297-300.

2. Van Nocker S, Ludwig P. The WD-repeat protein superfamily in Arabidopsis: conservation and divergence in structure and function. BMC Genomics. 2003; 4: 50.

3. Xu C, Min JR. Structure and function of WD40 domain proteins. Protein Cell. 2011; 2: 202-214.

4. Schapira M, Tyers $\mathrm{M}$, Torrent $\mathrm{M}$, Arrowsmith $\mathrm{CH}$. WD-repeat domain proteins: a novel target class? Nat Rev Drug Discov. 2017; 16: 773-786.

5. Wall MA, Coleman DE, Lee E, Iniguez-Lluhi JA, Posner BA, Gilman AG, Sprang SR. The structure of the G protein heterotrimer Gi alpha 1 beta 1 gamma 2. Cell. 1995; 83: 1047-1058.

6. Lambright DG, Sondek J, Bohm A, Skiba NP, Hamm HE, Sigler PB. The 2.0 A crystal structure of a heterotrimeric G protein. Nature. 1996; 379: 311-319.

7. Zeng CJ, Lee YR, Liu B. The WD40 repeat protein NEDD1 functions in microtubule organization during cell division in Arabidopsis thaliana. Plant Cell. 2009; 21: 1129-1140.

8. Walker AR, Davison PA, Bolognesi-Winfield AC, James CM, Srinivasan N, Blundell TL, Esch JJ, Marks MD, Graya JC. The TRANSPARENT TESTA GLABRA1 locus, which regulates trichome differentiation 
and anthocyanin biosynthesis in Arabidopsis, encodes a WD40 repeat protein. Plant Cell. 1999; 11: 1337-1349.

9. Shi DQ, Liu J, Xiang YH, Ye D, Sundaresan V, Yang WC. SLOW WALKER1, essential for gametogenesis in Arabidopsis, encodes a WD40 protein involved in 18S ribosomal RNA biogenesis. Plant Cell. 2005; 17: $2340-2354$.

10. Li HJ, Liu NY, Shi DQ, Liu J, Yang WC. YAO is a nucleolar WD40-repeat protein critical for embryogenesis and gametogenesis in Arabidopsis. BMC Plant Biol. 2010; 10: 169.

11. Han MJ, Jung KH, Yi G, Lee DY, An G. Rice Immature Pollen 1 (RIP1) is a regulator of late pollen development. Plant Cell Physiol. 2006; 47: 1457-1472.

12. Gao X, Chen Z, Zhang J, Li X, Chen G. OsLIS-L1 encoding a lissencephaly type-1-like protein with WD40 repeats is required for plant height and male gametophyte formation in rice. Planta. 2012; 235: 713-727.

13. Kumar S, Jordan MC, Datla R Cloutier S. The LuWD40-1 gene encoding WD repeat protein regulates growth and pollen viability in Flax (Linum Usitatissimum L.). PLoS One. 2013; 8: e69124.

14. Ju Y, Guo L, Cai Q, Ma F, Zhu QY, Zhang Q, Sodmergen. Arabidopsis JINGUBANG is a negative regulator of pollen germination that prevents pollination in moist environments. Plant Cell. 2016; 28: 2131-2146.

15. Yang HY, Li WS, Chen SN. Isolation and characterization of 4 gametophytic male sterile mutants in Arabidopsis thaliana. Chinese Sci Bull. 2007; 52: 1949-1956.

16. Preuss D, Rhee SY, Davis RW. Tetrad analysis possible in Arabidopsis with mutation of the QUARTET (QRT) genes. Science. 1994; 264: 1458-1460.

17. McCormick S. Control of male gametophyte development. Plant Cell. 2004; 16: S142-S153.

18. Swanson R, Edlund AF, Preuss D. Species specificity in pollen-pistil interactions. Annu Rev Genet. 2004; 38: 793-818.

19. Scott R, Hodge R, Paul W, Draper J. The molecular biology of anther differentiation. Plant Sci. 1991; 80: 167-191.

20. McCormick S. Male gametophyte development. Plant Cell. 1993; 5: 1265 -1275.

21. Bao S, Shen G, Li G, Liu Z, Arif M, Wei Q, Men S. The Arabidopsis nucleoporin NUP1 is essential for megasporogenesis and early stages of pollen development. Plant Cell Rep. 2019; 38 (1): 59-74.

22. Feng C, Wang JG, Liu HH, Li S, Zhang Y. Arabidopsis adaptor protein $1 \mathrm{G}$ is critical for pollen development. J Integr Plant Biol. 2017; 59 (9): 594-599.

23. Sun LP, Xiang XJ, Yang ZF, Yu P, Wen XX, Wang H, Abbas A, Muhammad Khan R, Zhang YX, Cheng $\mathrm{SH}, \mathrm{Cao} \mathrm{LY}$. OsGPAT3 plays a critical role in anther wall programmed cell death and pollen development in rice. Int J Mol Sci. 2018; 19 (12): 4017.

24. Yang ZF, Liu L, Sun LP, Yu P, Zhang PP, Abbas A, Xiang XJ, Wu WX, Zhang YX, Cao YL, Cheng SH (2019) OsMS1 functions as a transcriptional activator to regulate programmed tapetum development and pollen exine formation in rice. Plant Mol Biol. 99 (1-2): 175-191. 
25. Xu DW, Qu SY, Tucker MR, Zhang DB, Liang WQ, Shi JX. Ostkpr1 functions in anther cuticle development and pollen wall formation in rice. BMC Plant Biol. 2019; 19 (1):104.

26. Somaratne $Y$, Tian $Y H$, Zhang $H$, Wang MM, Huo YQ, Cao FG, Zhao L, Chen HB. ABNORMAL POLLEN VACUOLATION1 (APV1) is required for male fertility by contributing to anther cuticle and pollen exine formation in maize. Plant J. 2017; 90 (1): 96-110.

27. Sundaresan V, Springer P, Volpe T, Haward S, Jones JD, Dean C, Ma H, Martienssen R. Patterns of gene action in plant development revealed by enhancer trap and gene trap transposable elements. Genes Dev. 1995; 9: 1797-1810.

28. Jiang LX, Yang SL, Xie LF, Puah CS, Zhang XQ, Yang WC, Sundaresan V, Ye D. VANGUARD1 encodes a pectin methylesterase that enhances pollen tube growth in the Arabidopsis style and transmitting tract. Plant Cell. 2005; 17: 584-596.

29. Jia DJ, Cao X, Wang W, Tan XY, Zhang XQ, Chen LQ, Ye D. GNOM-LIKE 2, encoding an adenosine diphosphate-ribosylation factor-guanine nucleotide exchange factor protein homologous to GNOM and GNL1, is essential for pollen germination in Arabidopsis. J Integr Plant Biol. 2009; 51: 762-773.

30. Alexander MP. Differential staining of aborted and nonaborted pollen. Stain Technol. 1969; 44: 117122.

31. Spurr AR. A low-viscosity epoxy resin embedding medium for electron microscopy. J Ultrastruct Res. 1969; 26: 31-43.

32. Tan XY, Liu XL, Wang W, Jia DJ, Chen LQ, Zhang XQ, Ye D. Mutations in the Arabidopsis nuclearencoded mitochondrial phage-type RNA polymerase gene RPOTm led to defects in pollen tube growth, female gametogenesis and embryogenesis. Plant Cell Physiol, 2010; 51: 635-649.

33. Yang WC, Ye D, Xu J, Sundaresan V. The SPOROCYTELESS gene of Arabidopsis is required for initiation of sporogenesis and encodes a novel nuclear protein. Genes Dev. 1999; 13: 2108-2117.

34. Xia C, Wang YJ, Li WQ, Chen YR, Deng Y, Zhang XQ, Chen LQ, Ye D. The Arabidopsis eukaryotic translation initiation factor 3 , subunit $F$ (AtelF3f), is required for pollen germination and embryogenesis. Plant J. 2010; 63: 189-202.

35. Niu QK, Liang Y, Zhou JJ, Dou XY, Gao SC, Chen LQ, Zhang XQ, Ye D. Pollen-expressed transcription factor 2 encodes a novel plant-specific TFIIB-related protein that is required for pollen germination and embryogenesis in Arabidopsis. Mol Plant. 2013; 6: 1091-1108.

36. Zhou JJ, Liang Y, Niu QK, Chen LQ, Zhang XQ, Ye D. The Arabidopsis general transcription factor TFIIB1 (AtTFIIB1) is required for pollen tube growth and endosperm development. J Exp Bot. 2013; 64: 2205-2218.

\section{Tables}

Table 1. The primers used in this study 


\begin{tabular}{|c|c|}
\hline$\overline{\text { Primers }}$ & Sequences \\
\hline AtAPAM2-C-F & 5'-TACAAAGAAATGGACTAACTC-3' \\
\hline AtAPAM2-C-R & 5'-CTGTCAAGAACGATGAAC-3' \\
\hline AtAPAM2-P-F & $5^{\prime}$ - gctgcagctcttaaagggaagatttgtga-3' \\
\hline AtAPAM2-P-R & $5^{\prime}$-ctctagagaacttctgaaagacaaaatac-3' \\
\hline AtAPAM2-RT-F & 5'-GAGCCTGCTGCTATGGAATC-3' \\
\hline AtAPAM2-RT-R & 5'-TAGCTGACTCTGGCCCTTGT-3' \\
\hline TUBULIN-F & 5'-CTTCGTATTTGGTCAATCCGGTGC-3' \\
\hline TUBULIN-R & 5'-GAACATGGCTGAGGCTGTCAAGTA-3' \\
\hline atapam2-2-F & 5'-CCAGAGTCAGCTAACAATTTC-3' \\
\hline atapam2-2-R & 5'-CTTCTGTCTCAAACATGAAT-3' \\
\hline AtAPAM2GFP-F & = 5'-GGGGTACCGAGAGCAGAAGTTATGGAGTGGGCAACGGTGCAGCAT-3' \\
\hline AtAPAM2GFP-R & 25'ACGCGTCGACTTAGATGTTGATTAACACCAACGGTGA-3' \\
\hline
\end{tabular}

Table 2 Genetic analysis of atapam2-2/+ mutant

\begin{tabular}{cccc}
\hline Crosses (Female×Male) & Basta $^{\mathrm{R}}$ & Basta $^{\mathrm{S}}$ & Basta $^{\mathrm{R} B \mathrm{Basta}^{\mathrm{S}}}$ \\
\hline atapam2-2/+×atapam2-2/+ $^{1590}$ & 1500 & $1.06: 1$ \\
atapam2-2/+×WT & 851 & 900 & $0.95: 1$ \\
\hline WT×atapam2-2/+ & 0 & 2108 & $0: 1$ \\
\hline
\end{tabular}

Basta $^{R}$ : Basta-resistant; Basta ${ }^{S}$ : Basta-sensitive; WT: Wild-Type

\section{Figures}



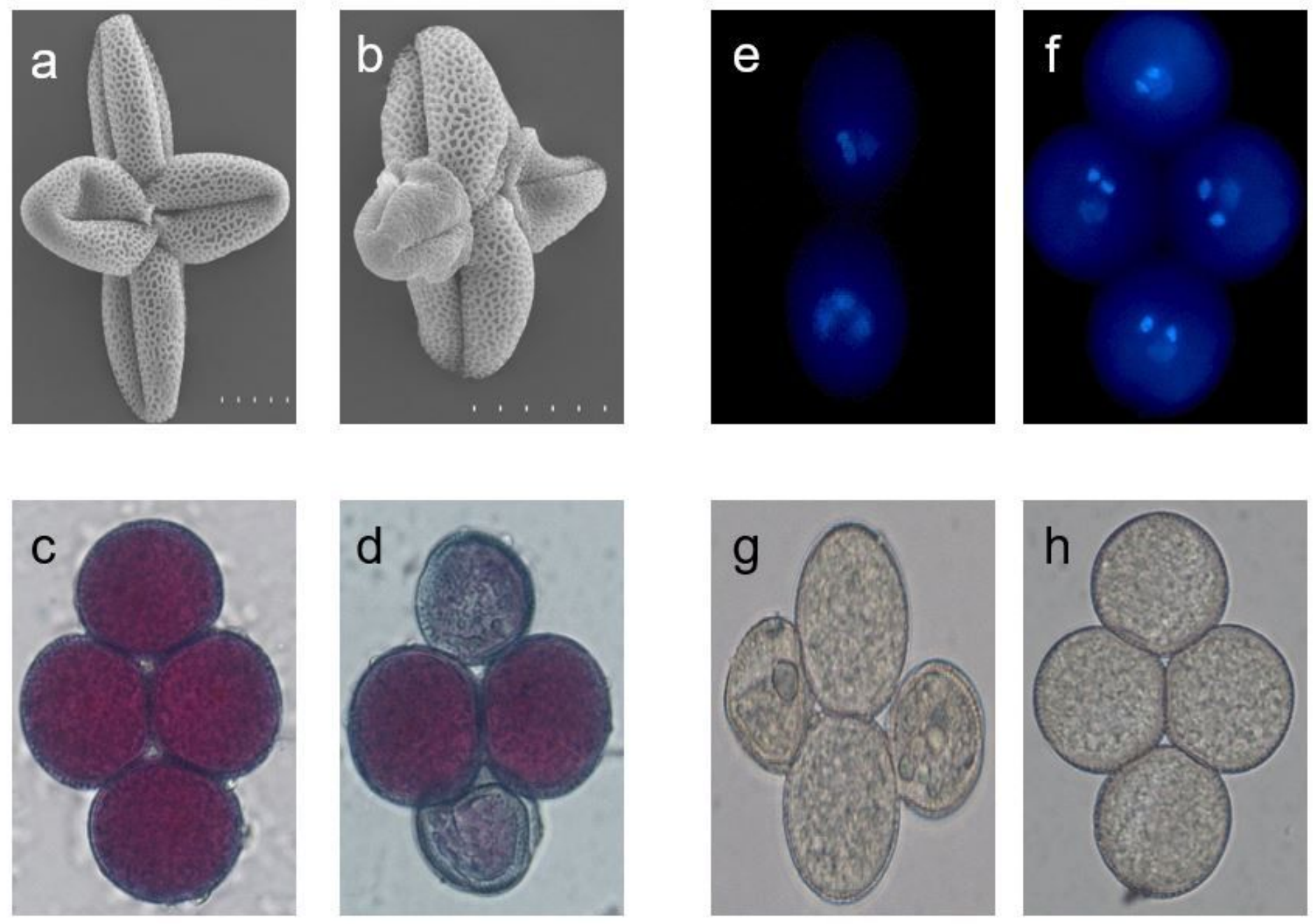

\section{Figure 1}

The phenotype of atapam2/+; qrt1/qrt1 pollen. a Scanning electron microscopy of pollen from qrt1/qrt1. b Scanning electron microscopy of pollen from atapam2/+; qrt1/qrt1. c Alexander staining of pollen from qrt1/qrt1. d Alexander staining of pollen from atapam2/+; qrt1/qrt1. e DAPI staining of pollen from atapam2/+; qrt1/qrt1. $f$ DAPI staining of pollen from qrt1/qrt1. $g$ and $h$ Bright fields of $e$ and $f$. 

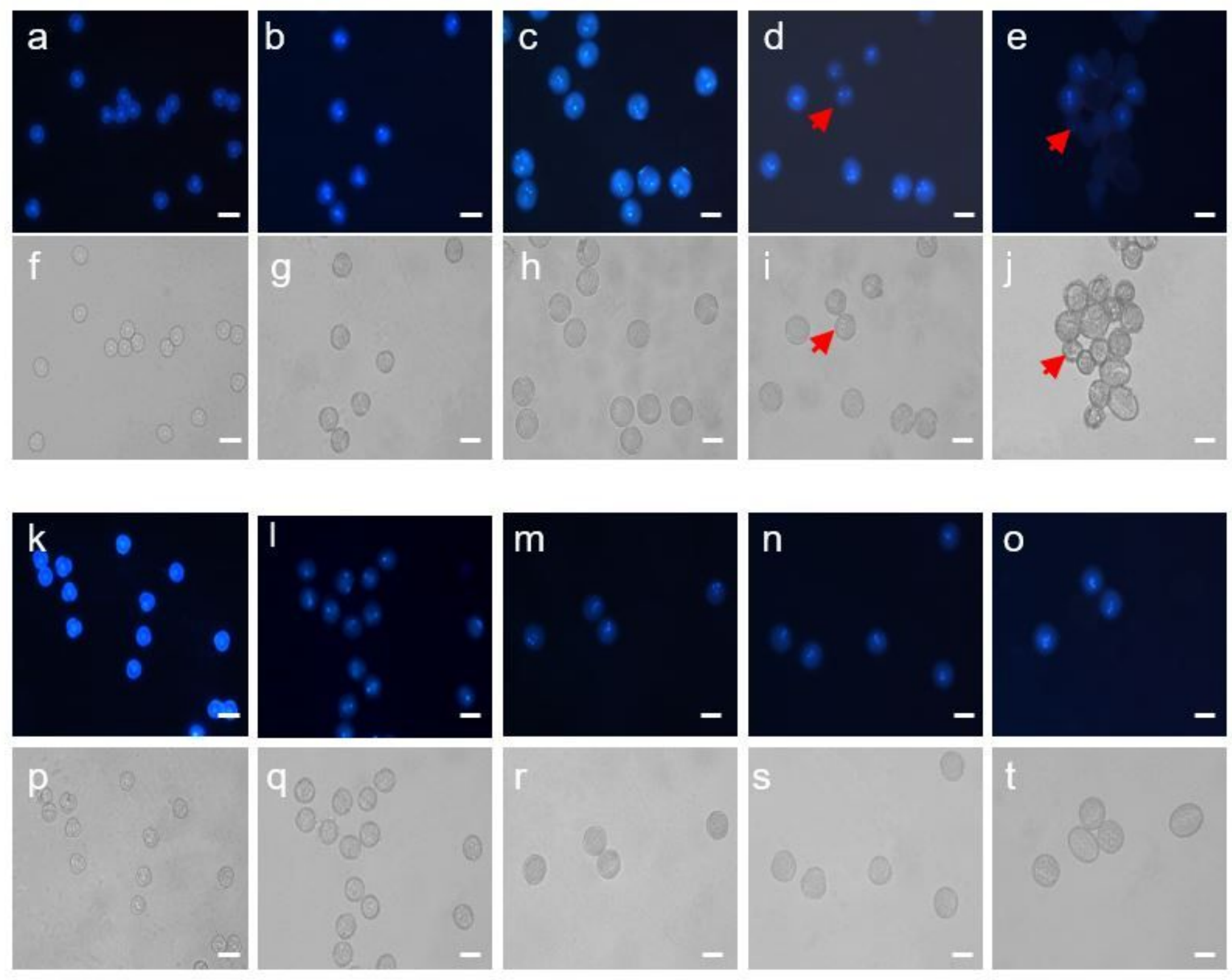

\section{Figure 2}

DAPI staining of different stages of pollen development. a, f, k, p Uninucleate pollen grains. b, g, l, q Binucleate pollen grains. $c, h, m, r$ Early trinucleate pollen grains. $d, i, n, s$ Middle trinucleate pollen grains. $e, j, o, t$ Late trinucleate pollen grains. a-e DAPI staining of different stages of pollen grains from atapam $2 /+. f-j$ Bright fields of a-e. $k-o$ DAPI staining of different stages of pollen grains from wild type. $p-t$ Bright fields of $k-0$. Red arrowheads indicate abnormal pollen grains. Bars $=100 \mu \mathrm{m}$. 

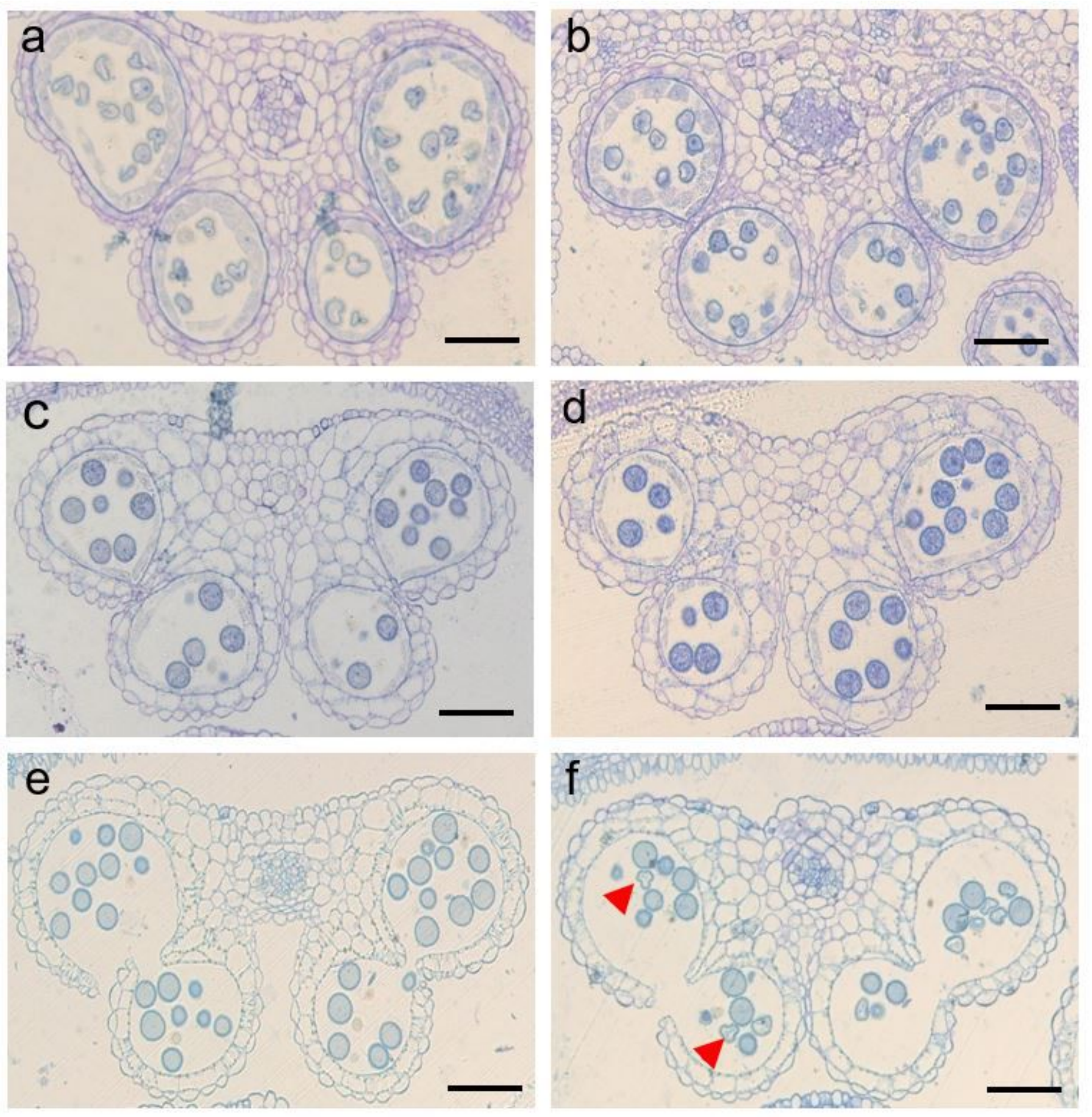

\section{Figure 3}

Semi-thin section images of anthers in wild-type and atapam $2 /+$ mutant. a, c, e Wild-type plants. b, d, $f$ atapam2/+ plants. a, b Stage 10 of anther development. c, d Stage 11 of anther development. e, f Stage 12 of anther development. Red arrowheads indicate the atapam 2 mutant pollen grains. Bars $=50 \mu \mathrm{m}$. 

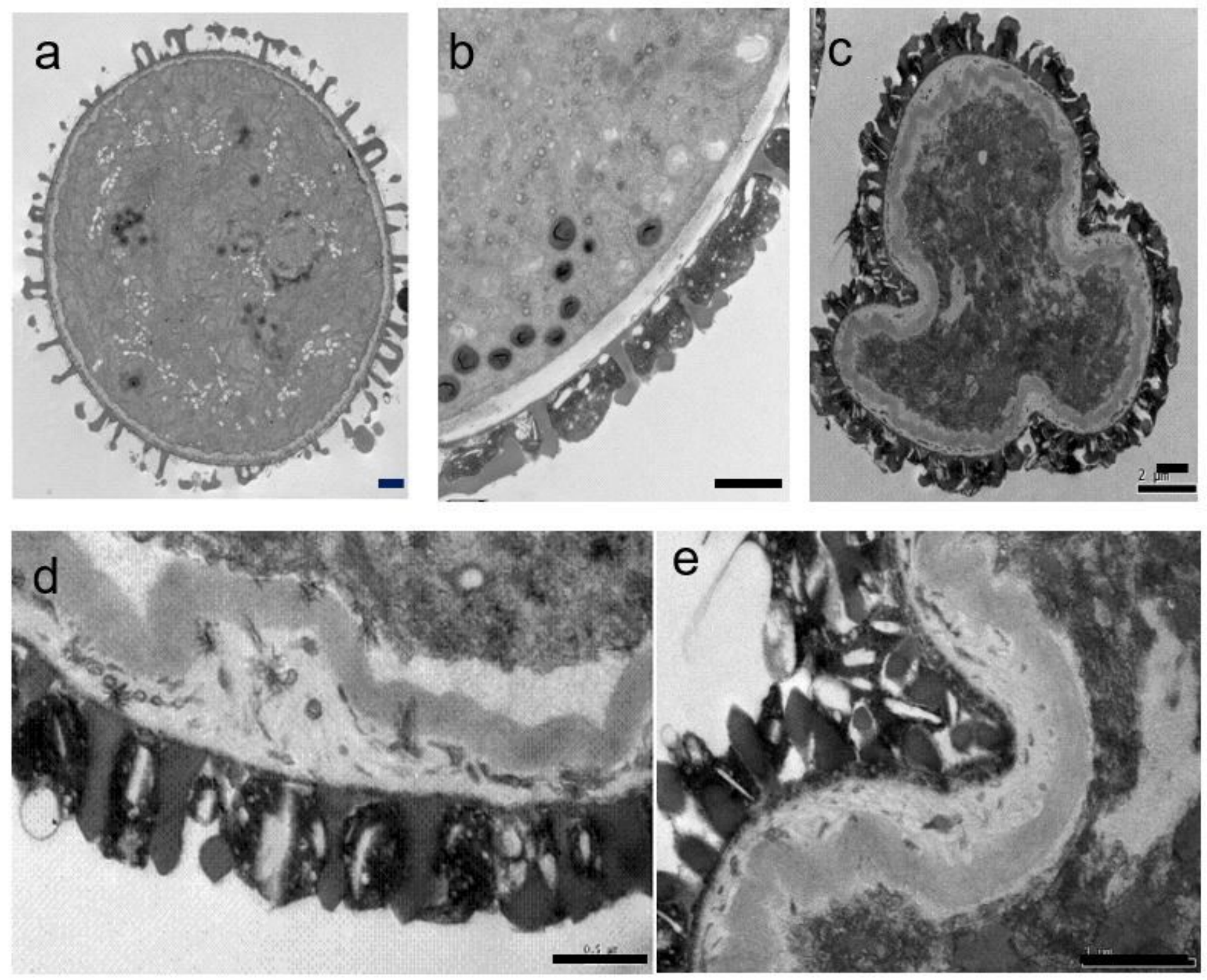

\section{Figure 4}

Transmission electron microscopy images of pollen grains from wild-type and atapam2/+. a, b wild-type. c-e atapam2/+. Bars $=1 \mu \mathrm{m}$. 

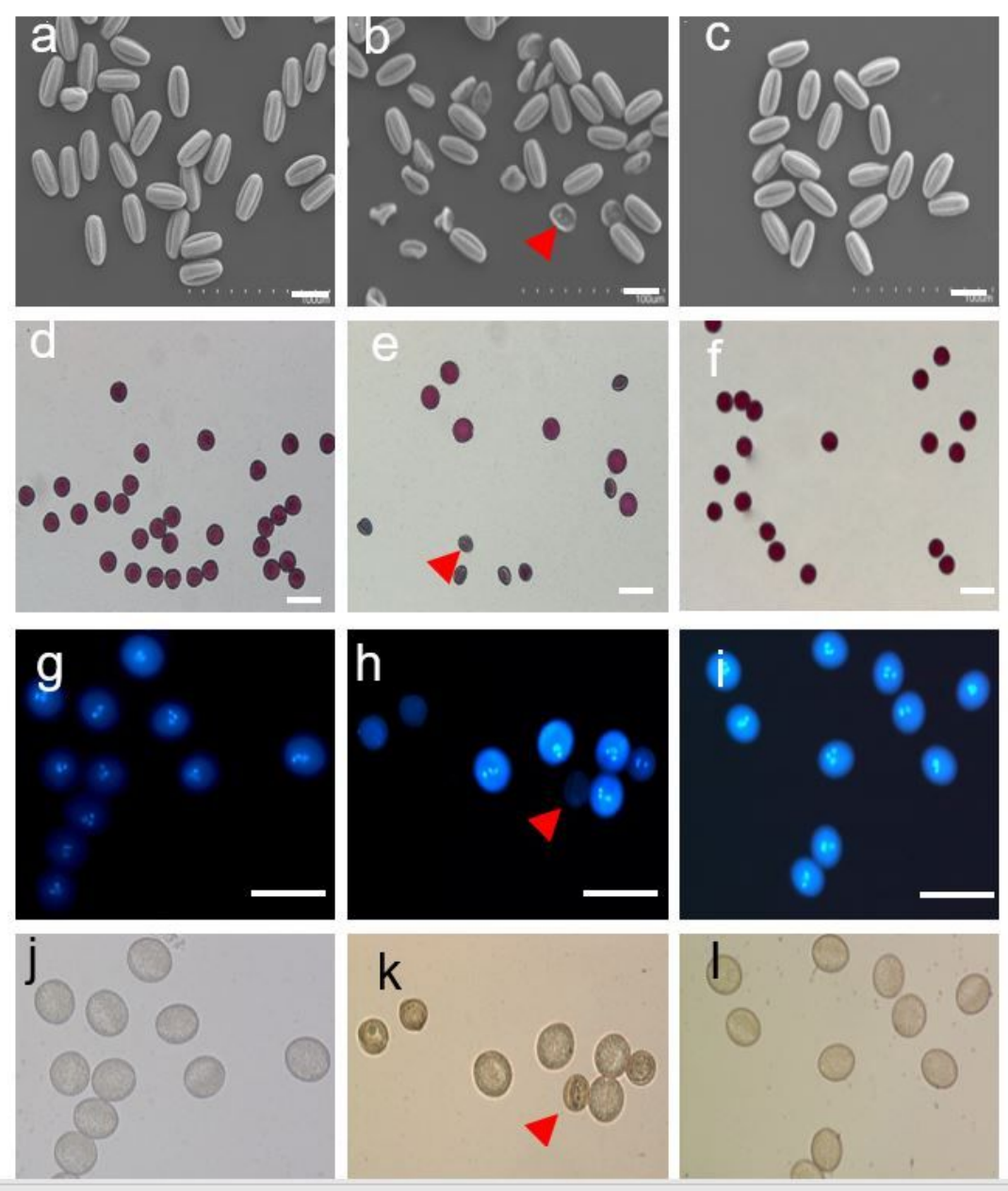

$\mathrm{m}$

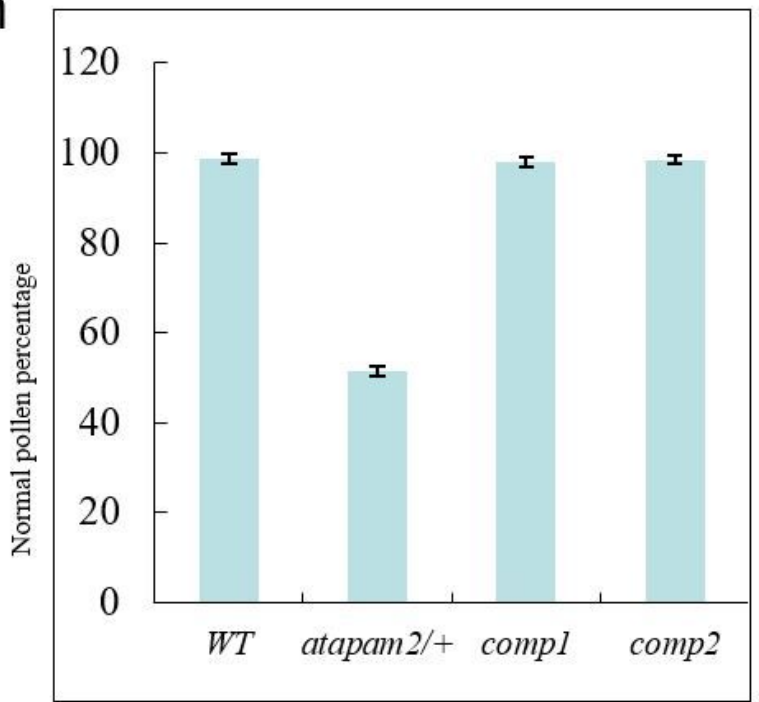

Figure 5

Characterisation of atapam $2 /+$ mutant pollen grains and complementation plants pollen grains. a-c Scanning electron microscopy image of pollen grains from wild-type, atapam2/+ mutant, and complementation plants. $d-f$ Alexander-stained pollen grains from wild type, atapam $2 /+$ mutant, and complementation plants. $\mathrm{g}-\mathrm{i}$ DAPI-stained pollen grains from wild type, atapam2/+ mutant, and complementation plants. $j-I$ Light field of $g-i$. $m$ Statistics of normal pollen percentage from wild type, atapam2/+ mutant, and complementation plants. Bars $=100 \mu \mathrm{m}$ in a-f and $50 \mu \mathrm{m}$ in $\mathrm{g}-\mathrm{I}$. 
a
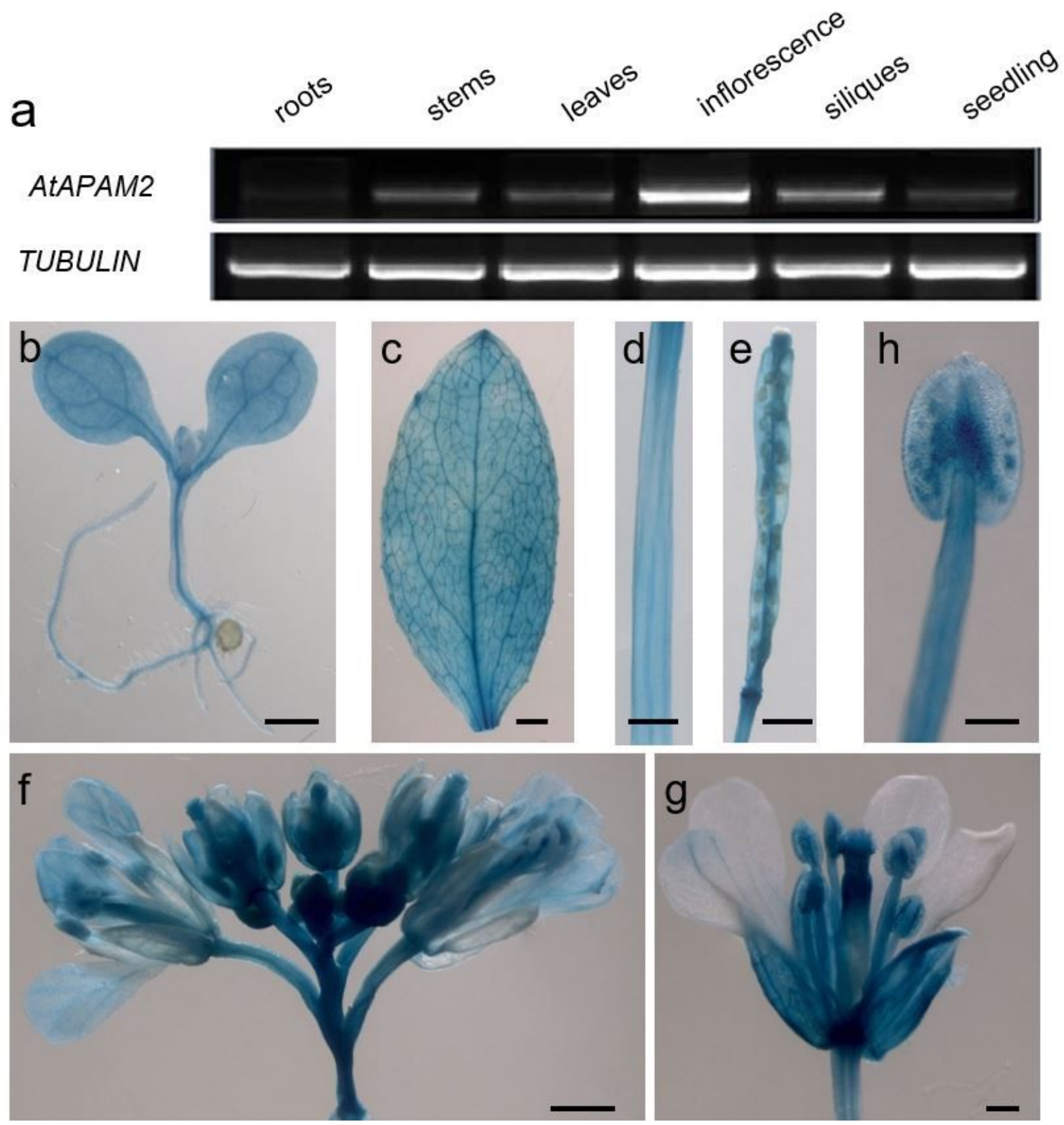

\section{Figure 6}

Expression pattern of AtAPAM2. a RT-PCR assay comparing AtAPAM2 mRNA levels in roots, stems, leaves, inflorescences, siliques, and seedlings. Expression level of TUBULIN was used as an internal control. b-h GUS activity in seedlings (b), mature leaves (c), stems (d), siliques (e), inflorescences (f), flowers $(\mathrm{g})$, and anthers $(\mathrm{h})$ from transgenic wild-type plants carrying the pAtAPAM2:GUS construct. Bars $=500 \mu \mathrm{m}(\mathrm{b}-\mathrm{f})$ and $100 \mu \mathrm{m}(\mathrm{g}, \mathrm{h})$. 

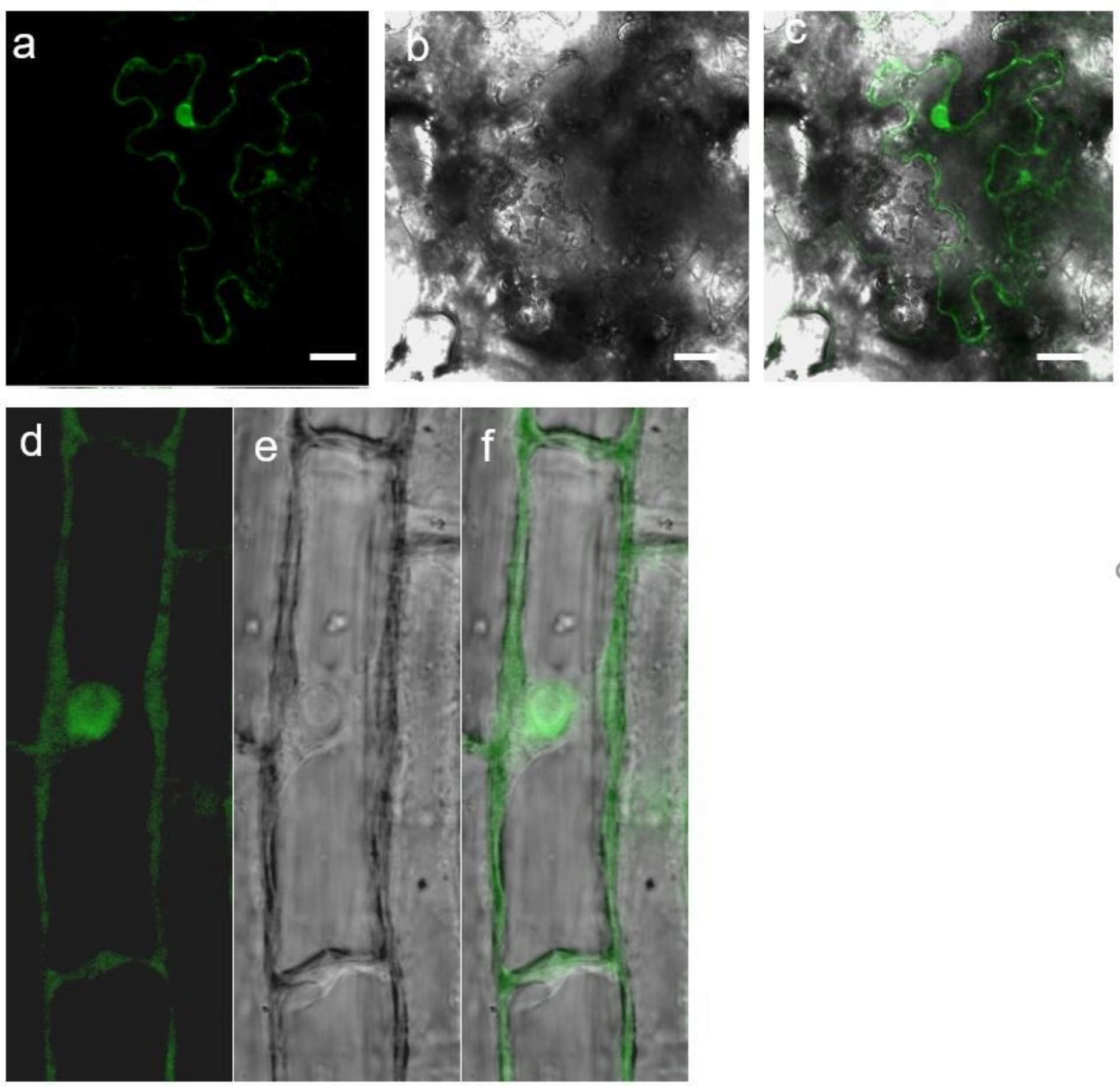

\section{Figure 7}

Subcellular localisation of AtAPAM2 protein. a-c Transient expression of p35S:GFP-AtAPAM2 in epidermal cells of Nicotiana benthamiana, showing localisation of AtAPAM2 protein in plasma membrane and nucleus. a GFP image. $b$ Bright field image of $a$. c Merged image of $a$ and $b . d-f$ Stable expression of p35S:GFP-AtAPAM2 in roots of Arabidopsis, showing localisation of AtAPAM2 protein in plasma membrane and nucleus. $d$ GFP image. e Bright field image of $d$. $f$ Merged image of $d$ and e. Bars $=20 \mu \mathrm{m}$. 
a

AtAPAM2

ATG

b

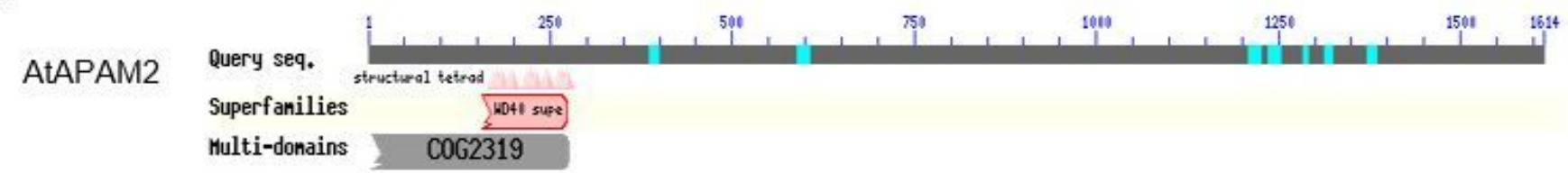

C

NETATVQHLD LRHVGRGVSR PLQPHTAARH PSQAVIAVAV GSHINGFDAL TGCXIASIDI GSPAVRLYYS PTSSNAVVAI LBDCTIRSCD FETEQTCVLH SPEXRSEHIS SDTEVHLAVI PLQPVVFFG PKRUSVTVVG TVEGGRAPTX IXTDLXXPIV NIACHPRLPV LYVAYABGLI RAYNIHTYAV HYTLQLDNTI XLIGASSFAF HPTLEVIFVG DRRGTLLAND VSTERPNUIO

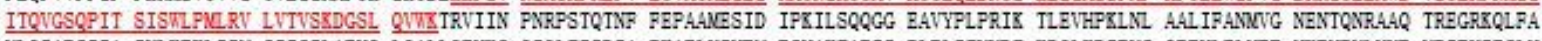
VLQSARGSSA SVLXEXLLSN GSSGILAEHQ LQALLQEHKG QSQLTISDIA RX.AFLYSHFN BGHAKTAPIS RLPLITVVDT XDQLXDIPVC QPFHLELNFF NXPNRVLHYP VRSFYIBGLN LNAHNLCSGT DNIYXXLYTS IPGNVEYHSX HIVYSRKRHL FLVYFEFSGA TNZVYLYWEN TGSQLPNSXG STAXGCDALF IGPNDDQFAI LDEDXTGLSN YILPXLTTNE ENEXNLLSEE

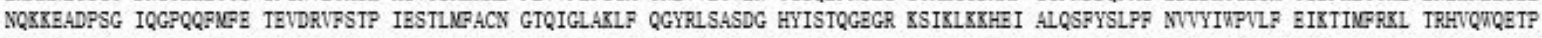
RGYVAGILTT QRVLNVSLLT VGPALLFSTT TAVCLLGUDG IVRTILSIST PYAALVGALN DRLLLAHPTD ISPXQXXGIE IXSCLVGLLE PLLIGFSTNQ QTFEQRVDLS EILYQITTRF DSLRITPRSL DILARSAPVC GDLAVSLAQA GPQFNQVLRC AYAIXALRFS TALSULXDER LRSRDYPXCP PTSLLFQRRR QLGYACIXYG QFDSAXETFE VIGDYBSMLD LFICHLNPSA

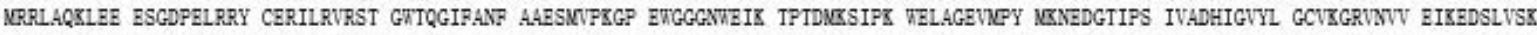

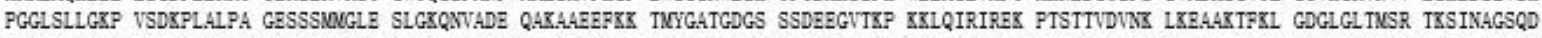
LGQNLSQPSS STVATTTAPS SASAPVDPFA NSSWTQQPQP VSQPAPPGVA APIPEDFFQN TIPSVEVAXT LPPPGTYLSX NDQA.ARAAIA AQGGPNQANX TPLPDIGLPD GGVPQQYPQQ TSQQPGAPFQ TVGLPDGGVR QQYPGQNQVP SQVPVSTQPL DLSVLGVPNT GDSGXPPGQP QSPPASVRPG QVPRGAAAPV CFRTGLAHLE QNQLPDALSC FDEALILAL.AK DQSRGADIKA

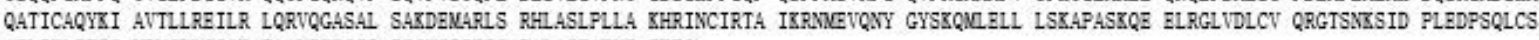
ATLSRLSTIG YDVCDLCGAK FAALSSPGCI ICGNGSIXRS DALAGPAPVS TPFG

d

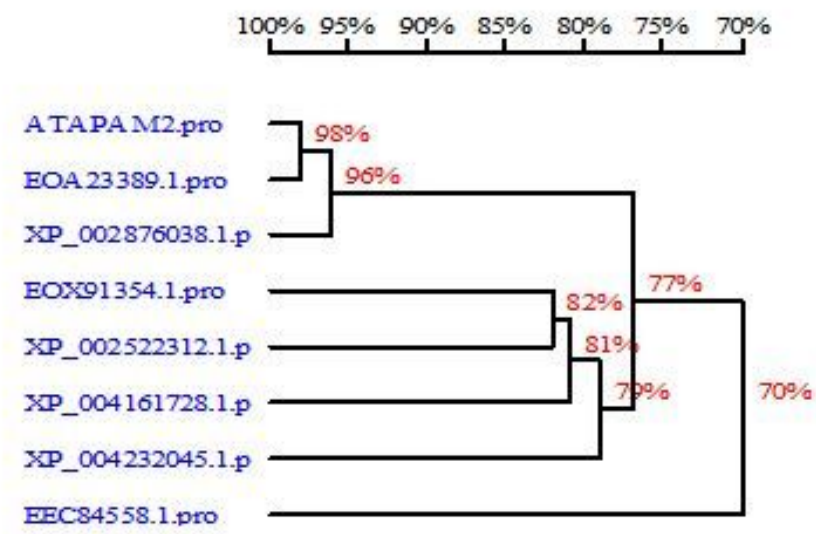

\section{Figure 8}

Molecular characterisation of the AtAPAM2 gene. a Schematic diagram of AtAPAM2 structure, showing the Ds insertion site in the atapam2/+ mutant and T-DNA insertion site in the atapam2-2 mutant. Black boxes indicate coding sequences and lines indicate introns. b Putative conserved domains of AtAPAM2 detected. c Predicted peptide sequence of AtAPAM2, showing the conserved domains. WD40 domains are shown by underline and red characters. $d$ The sequence similarity analysis of AtAPAM2 and similar proteins from different species. AtAPAM2, Arabidopsis APAM2 protein; EOA23389.1, Capsella rubella; EEC84558.1, Oryza; XP_002522312.1, Ricinus communis; XP_004232045.1, Solanum lycopersicum; 
XP_004161728.1, Cucumis sativus; EOX91354.1, Theobroma cacao; XP_002876038.1, Arabidopsis lyrata subsp. Lyrata. 